\title{
Experimental Investigation on Flange Bolted-Welded Connection for Steel Frame
}

\author{
Y.F. Jiao, X.M. Liu \\ Department of Civil Engineering \\ Henan University of Science and Technology \\ Kaiyuan Road 263 \\ Luoyang,China.
}

\begin{abstract}
This paper proposes a new type of splice joint, named flange bolted-welded hybrid joint, which is designed to splice Ishape beam to facilitate the construction of industrialized buildings. The flange, welded with the bottom beam flange as well as the web close to bottom flange, are jointed by high strength bolts. Stiffening plate is welded at top of the flange while downhand welding and high strength friction grip bolts are used for the top beam flange and the beam web, respectively. The connection reduces the construction period and costs. In this paper, monotonic and reversed cyclic loading tests were conducted on three full-scale specimens of this innovative joint, to investigate its load-bearing capacity, energy-dissipating capacity and failure modes. The results indicate that the joint has high load-bearing capacity and great ductility. The failure mode is due to the slippage of flange bolts as well as the gap development between the two flange plates. The experimental studies enabled improvement of the design of the connection to be used in moment-resisting steel frame structures.
\end{abstract}

Keywords-flange bolted-welded hybrid joint; monotonic testp; cyclic test; finite element analysis

\section{INTRODUCTION}

Beam-to-beam and beam-to-column connections have been found to have a great influence on structural behavior. Now the traditional connections, such as welded, bolted and welded-bolted hybrid connection, are widely adopted for their better mechanical properties. However, the welded and bolted joints have some drawbacks. Take the welded joint as an example, improper welding practice, poor workmanship would result in some yield strength variations of the material and brittle fractures, which could strengthen the high stress concentration[1]. As a result, strict quality control measures should be taken to prevent the unexpected failure of welded connection. That means a relative high cost of labor force and long installation period. In recent years, the attention of connection flexibility and its effects on the behavior of steel structure has been paid gradually by researchers. Therefore, a lot of improved joint details have been proposed in two aspects. One is to reduce the stress concentration of the joint zone and the other is to move the plastic hinge away from the beam-to-column connection region. Specifically, two key concepts have been developed to provide shifting of plastic hinge: reduced beam section connection and reinforced connections. A reduced beam section is proposed to create a weak point in the beam element, which modifies the ductility of the connection but may be vulnerable to stress concentration at the beam web and then decreases moment capacity significantly[2]-[5] . As the modified measure, HoomanFarrokhi[6]. proposed drilled holes at cover plates to create an intentional weak point, while it seems to be less efficient. In addition, J.M.Ricles[7]-[9]have developed a posttensioned(PT) steel moment connection with bolted top and seat angles for seismic resistant MRFs. Constantin Christopoulos[10]conducted a cyclic test on a large-scale exterior beam-to-column PT connection. The connection avoids field welding, reduces beam damage, and eliminates residual drift, but increases the difficulty of installation due to its complex details. As for reinforced connections, a variety of methods have been used to reinforce connections in hopes of achieving large cyclic plastic rotations before connection failure happens[11]-[13] . While promising better performance, the reinforced connections have also experienced failures in laboratory tests, and introduce potential new problems.

In a word, the efforts concentrate on the improvements in welding and modifications to the connection design. Though the joints with modifications achieved better seismic behavior, these modification details of the joints are relative complex and time-consuming in fabrication. It should be noted that the high level of industrialization will have great impact on project costs because of the growing labor price. Therefore, the connection with both good energy dissipation capacity and modern construction technology should be designed and studied. As a result, a new type of connection, named flange bolted-welded connection, is designed in aiming at accelerating construction speed, improving joint behavior and satisfying construction of industrialized buildings.

Based on these defects, the proposed joint, named flange bolted-welded joint, aims to enhance the seismic behavior as well as convenient installation. The flange bolted-welded splice connection, as an improvement on column-tree connection, didn't fail owing to welding fracture because of its reasonable force transfer mechanism.

The flange, welded with the bottom beam flange as well as the web close to bottom flange, are jointed by high strength bolts. A stiffening rib is welded at top of the flange while downhand welding and high strength friction grip bolts are used for the top beam flange and the beam web, 
respectively(shown in Fig. 1. ). After installing the web and bottom flange bolts, the top flanges are connected by downhand welding, that is easy to implement.

Owing to a small number of bolts being used and convenient operation of the downhand welding, this new type of joint meets the requirements of industrialization of building. Its distinguished feature lies in simple assembly method, overcoming the over-consuming of force labor on site.

In order to further investigate the proposed joint behavior, three full-scale specimens were tested under the monotonic and reversed cyclic loading tests, and used as the calibration basis for the numerical studies. Accurate finite element models were then developed to simulate the performance of the connection, with emphasis on the behavior of the flange plates. Finally, extensive parametric studies were conducted to investigate the influence of steel strength, flange bolt diameter, flange plate thickness on the structural behavior of joints. Based on the experimental and numerical studies, the feasibility of the connection to be used in moment-resisting steel frame structures has been explored.

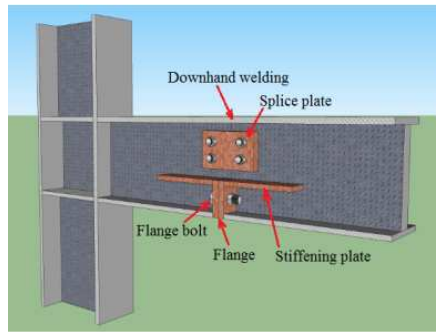

FIGURE I. DETAILS OF FLANGE BOLTED-WELDED CONNECTION OF STEEL BEAM

\section{EXPERIMENTAL PROGRAM}

\section{A. Test Specimens}

Three experimental full scale connection specimens, named SPJ1-1, SPJ2-1 and SPJ2-2, were fabricated to appraise the performance of the proposed joint. High strength bolts at web of the beam is used to resist shear force. In view of the same occurrence possibility of the hogging and sagging moment at the splice, the bottom beam flanges are connected by flange plates and high-strength bolts. The flange plates can transfer hogging moment by tightly contact action. On the other hand, the flange high strength bolts were designed to resist sagging moment. As the beam section centre is taken as rotational centre, the number of flange bolts can be determined by distance between bolts and rotational centre.

The flange plate is taken as a three-sides bearing plate for being welded by stiffening rib, cross profile of beam web and beam flange respectively. Therefore, after obtaining the moment of flange plate, the thickness of splice flange plates can be calculated from Eq.(1), based on the small deflection bending theory of thin plate.

$$
t \geq \sqrt{\frac{5 M_{\max }}{f}}
$$

where: Mmax is the maximum moment of the splice flange plate per unit width and $f$ is design value of strength of flange plate.

Figure. 2 provide the design details of the flange boltedwelded joint. The bolts at web and bottom flange were Grade $8.8 \mathrm{M} 20$ and Grade 10.9 M30 respectively. These bolts were tightened to $125 \mathrm{kN}$ and $355 \mathrm{kN}$ pretention force respectively following the specification GB50017[14] .

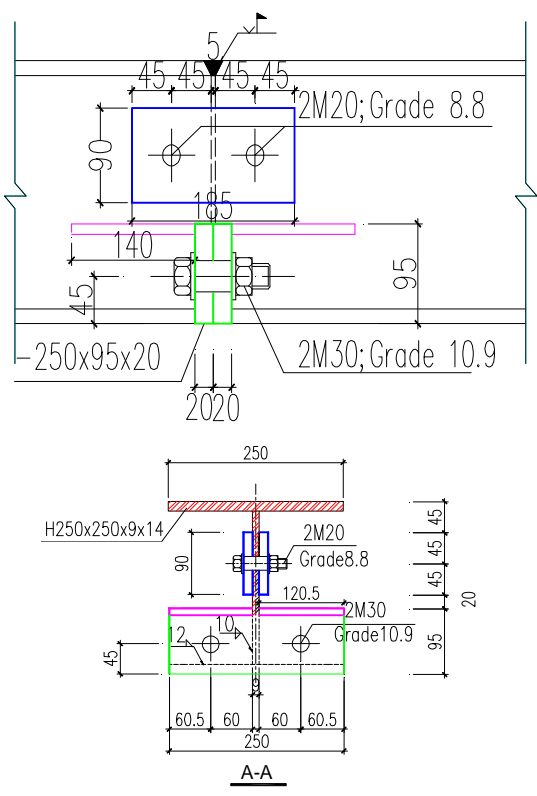

FIGURE II. DESIGN DETAILS OF SPECIMENS

\section{B. Test Setup and Loading Program}

In order to investigate the ultimate bearing capacity and seismic response, the specimen SPJ1-1 was tested under downward monotonic loading while SPJ2-1 and SPJ2-2 were tested under cyclic loading. The hydraulic actuator of $1000 \mathrm{kN}$ capacity, fastened with reaction frame, was used to apply load on beam end in the vertical direction. A lateral bracing was placed at the beam for preventing out-of-plane instability of the specimens. The column foot was bolted to the lab by anchor bolts. Meanwhile the top of the column is connected to the reaction frame, as illustrated in Fig. 3, which also displays the four displacement transducers layout. In order to measure the bending resistance and shear bearing capacity of the beam, the unidirectional strain gauges were arranged at beam flange. Besides, strain rosettes were used at flange plate and its stiffening rib(shown in Fig.3).

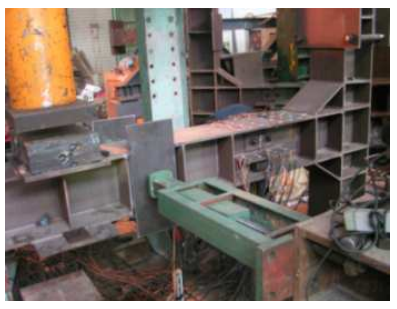

FIGURE III. PHOTOGRAPH OF TEST SETUP 
The test procedure of specimen SPJ1-1 was divided into two different phases: the preloading phase and the loading phase. In the preloading phase, all the measurement channels were scanned to record the initial readings before any loads were applied. Then, the loads were increased by $10 \mathrm{kN}$ and then decreased to zero. In the loading phase, the force control mode was adopted, with load increments of $40 \mathrm{kN}$ from $40 \mathrm{kN}$ to failure. The specimen SPJ2-1 and SPJ2-2 were tested by force-displacement control mode during their cyclic loading procedure. From the load-displacement curve recorded during the monotonic test, the limit of elastic range $\mathrm{Fy}$ and the corresponding displacement $\triangle \mathrm{y}$ may be deduced.

\section{Results and Discussion}

SPJ1-1 was applied monotonic downward load. The observed failure modes of ultimate load are illustrated in Fig.4 . It was found that the shear deformation occurred at column-beam connection region accompanied by the buckling of stiffening rib. The reason is that the bottom part of beam flanges are linked by flange plate, which could transfer pressure owing to their tightly contact and compression action under downward loading. This action is so strong that the beam splice part had no obvious deformation as well as rotational angle.

SPJ2-1 and SPJ2-2 were experienced cyclic loading process and the two specimens behaved similarly. Take SPJ2-2 as an example to comment on the experiment. When cyclic loading $\mathrm{P}$ up to $\pm 180 \mathrm{kN}$, the gap between two flanges connecting the bottom beam appeared. In the next cycle, the nuts of the web bolts slip slightly, with the bottom flange gap reaching to 13 $\mathrm{mm}$. At this load stage, the haunched support at beam-column connection part buckled coupled with shear deformation at beam-column connection. The gap between the flanges was gradually enlarged with the increase of load, which brought about the slippage of the flange bolts. The specimen lost its bearing capacity due to the falling off of the nuts at last. The ultimate displacement of the beam end was $120 \mathrm{~mm}$.

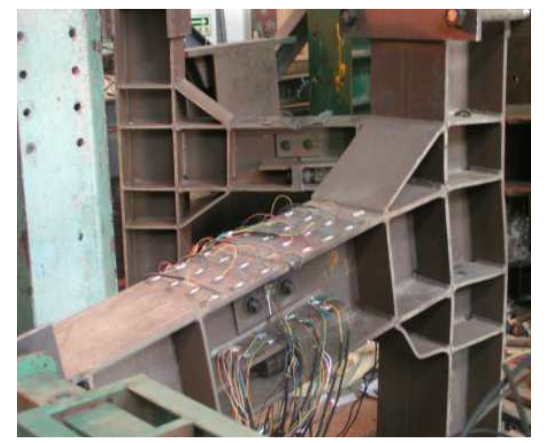

FIGURE IV. FAILURE MODES OBTAINED FROM TESTS

The hysteretic curve is plotted in Fig.5, which also displayed bending moment design value of the joint, as the horizontal line indicated. Rotation angle is defined as the displacement at load point divided by the distance between the joint and the load point. The apparent characteristic of the hysteretic curve is that the displacement generated by upward load is bigger and curve shape is plumper than that of downward load, which agree with the joint mechanical principle. To be specific, when beam end were subjected to upward load, the gap between the flanges occurred together with the slippage of the flange bolts. Afterwards, when load was reversed, two flanges stayed close again after the gap elimination. So the total displacement of the beam end contained the displacement brought about by the gap closing process. In addition, the contact action between two flanges was so strong that made the displacement relatively small under downward load. Therefore, the displacements of the two direction weren't symmetrical, manifesting the different response and capacity for the positive and negative moment of the beam, which comply with design principle of the joint. It can also be seen from figure 8 that the positive and negative ultimate moment capacity reached to $261.3 \mathrm{kN}$.m and $345 \mathrm{kN}$.m, respectively. Compared to the bending moment design value, the joint behaved better performance of bearing capacity.

As discussed above, the flange interfaces were alternately subjected to separation and contact condition, which made the flange bolts loosing tightness. At last, the specimen failed because of the nut slippage and then collapse.

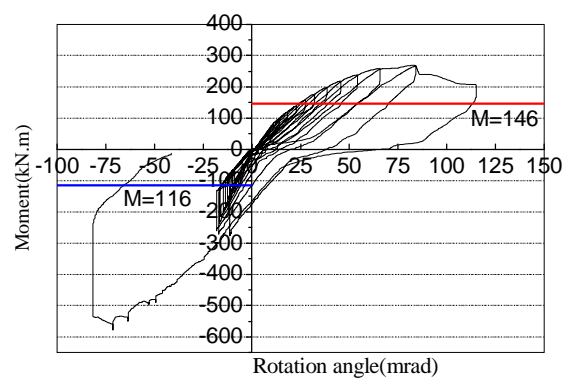

FIGURE V. MOMENT-ROTATION ANGLE CURVES OF SPJ2-2

\section{CONCLUSION}

Based on the numerical and experimental investigations performed on full-scale connection models the following conclusions can be made:

(1) The specimens under cyclic loading failed with the complete loss of pretension. As the important component of the joint, the splice flanges transferred the moment effectively through the strong contact action between the two flanges .

(2) Under the monotonic loading, the thickness of the flange plates significantly affect the stiffness and the moment capacity of the connection and hence shall be dimensioned precisely to fulfill the design demands. Moreover, the ultimate moment capacity of the connection increases with the steel strength.

The proposed connection can not only facilitate the rapid construction and industrialization, but meet requirements for resistance for moment frames. Furthermore research, however, is recommended to employ to explore the joint response with bigger size of beams and columns.

\section{REFERENCES}

[1] FEMA. State of the art report on welding and inspection.Report No.FEMA-355B.Federal Emergency Management Agency;2000.

[2] Chen SJ, Yeh CH, Chu JM. Ductile steel beam-to-column connections for seismic resistance[J]. Journal of Structural Engineering 1996;122(11):1292-1299.

[3] Astaneh A, Nader MN. Cyclic behavior of frames with semi rigid connections. In: Proceedings of the second International workshop 
connections in steel structures II. 1991.

[4] Chou-Chang che, Chia-Ching Wu. Performance evaluation of steel reduced flange plate moment connections. Earthquake Engineering \& Structural Dynamics 2007;36(14):2083-2097.

[5] Chen SJ, Chu JM, Chou ZL. Dynamic behavior of steel frames with beam flanges shaved around connection[J]. Journal of Constructional Steel Research,1997,42(1):49-70.

[6] HoomanFarrokhi , F. Danesh, SassanEshghi. A modified moment resisting connection for ductile steel frames (Numerical and experimental investigation). Journal of Constructional Steel Research 2009;65(12):2040-2049.

[7] Ricles JM, Sause R, Garlock MM, Zhao C. Post-tensioned seismicresistant connections for steel frames. Journal of Structural Engineering 2001;127(2):113-121.

[8] Ricles JM, Sause R, Peng SW, Lu LW. Experimental evaluation of earthquake resistant post-tensioned steel connections. Journal of Structural Engineering 2002; 128(7):850-859.

[9] Garlock MM, Ricles JM, Sause R. Experimental studies of full-scale post-tensioned steel connections. Journal of Structural Engineering 2005; 131(3):438-448.

[10] Christopoulos C, Filiatrault A, Uang C-M, Folz B. Post-tensioned energy dissipating connections for moment resisting steel frames. Journal of Structural Engineering 2002; 128(9):1111-1120.

[11] Engelhardt MD, Sabol TA. Reinforcing of steel moment connections with cover plates: benefits and limitations. Engineering Structures 1998;20(4-6):510-520.

[12] Lee CH. Seismic design of rib-reinforced steel moment connections based on equivalent strut model. Journal of Structural Engineering 2002;128(9):1121-1129

[13] Uang CM, Bondad D, Lee CH. Cyclic performance of haunch repaired steel moment connections: experimental testing and analytical modeling. Engineering Structures 1998;20(4-6):552-561.

[14] GB50017-2003. Code for design of steel structures. Beijing: China Planning Press;2003 [in Chinese]. 